\title{
EDUCATION
}

\section{Knowing and Teaching Elementary Mathematics- How Are We Doing?}

\section{Roger Howe}

Knowing and Teaching Elementary Mathematics (KTEM) by Liping Ma [10], based on a comparative study of the mathematical understanding of US and Chinese elementary mathematics teachers, was published in 1999. It landed in the US mathematics education community like a bombshell. It also attracted substantial interest internationallyit has been translated into Chinese, Korean, Spanish, and Czech.

For much of the second half of the twentieth century, US mathematics educators had been debating the role of the mathematical knowledge of teachers in fostering mathematics learning. Some studies [5] had indicated that the correlation between the amount of college mathematics training of teachers and the achievement of their students was very weak, and perhaps even negative. In [19], Lee Shulman proposed that perhaps content knowledge of teachers needed to be thought about differently, and that there is content knowledge that is specific to teaching, different in nature from the knowledge that engineers, scientists, and mathematicians need to ply their crafts. Taking a cue from Shulman, Deborah Ball [1-3] started investigating what might be the nature of that knowledge, which she later [4] called Mathematical Knowledge for Teaching (MKT). With some colleagues at the National Research Center for Teacher Education (NCRTE) at Michigan

Roger Howe is William R. Kenan, Jr., Professor Emeritus of Mathematics at Yale University, and Curtis D. Roberts Endowed Chair in Mathematics Education at Texas A\&M University. His email address is roger. howe@yale.edu.

Communicated by Notices Associate Editor William McCallum.

For permission to reprint this article, please contact:

reprint-permission@ams.org.

DOI: https://doi.org/10.1090/noti2102
State University, she developed a set of interview questions for gauging knowledge that plausibly could contribute to MKT and which could only be correctly answered with a good understanding of several key ideas of elementary math: the reasons behind the computational algorithms for subtraction and multiplication, the meaning of division by fractions, and the relationship between area and perimeter. See [9].

Liping Ma took these four questions, translated them into Chinese, and went to China to pose them to a group of Chinese teachers. The teachers were not randomly selected, but did represent several types of teaching situations: different grade levels, urban and rural, etc. She compared the results of her interviews to those of a group of US teachers who had been interviewed with the NCRTE questions. These teachers had been described as "better than average" in the US by an expert who had worked with them.

The results from the two sets of interviews were strikingly different: the Chinese teachers provided dramatically superior responses, especially to the more challenging questions. The group of Chinese teachers collectively showed a level of expertise in elementary mathematics that was off the charts relative to US experience.

Dramatic as these results were, KTEM went considerably beyond a simple report of comparative performance. Ma formulated a concept of "profound understanding of fundamental mathematics" (PUFM) that captured the knowledge level of the best of the Chinese teachers, and she investigated how these teachers arrived at this level. This further work made clear that, in some sense, it was not fair to compare American teachers to their Chinese counterparts. Although the Chinese teachers benefited from good training 
in $\mathrm{K}-12$ and college, their approach to and achievement of PUFM involved continued learning over their years of teaching, and this learning was enabled by their work conditions, conditions which were drastically different from those of US teachers, especially with respect to supporting professional growth.

For one thing, even at the elementary level, most of the Chinese teachers were specialists who were only responsible for learning mathematics and could concentrate on it. For another, many of the Chinese teachers had "taught in rounds", following the same class through several years, so that they had a perspective on how mathematics learning develops over a range of years. Third, at the expense of running larger classes (more like 40+ than 30-), the Chinese teachers were required to be in the classroom only half or less of each school day. The rest of the day they could spend grading, working with students who needed extra attention, studying the teaching materials (mainly textbooks, officially produced and highly focused on the mathematical issues of each lesson; and also the Chinese mathematics standards). Most saliently, they had time and opportunity to talk with colleagues about teaching issues. These discussions were facilitated by the fact that usually the math teachers had a common office where they would go to work when not teaching.

Thus, the Chinese elementary mathematics teachers enjoyed a workday that promoted continual learning, and over the years, this helped many of them to achieve an impressive grasp of the key issues of their elementary mathematics curriculum. At the time that KTEM was published, it was not possible to evaluate directly how this superior teacher knowledge translated into student achievement (although Ma did present evidence that it did). However, when Shanghai was ranked \#1 in the world when it first (2012) participated in the Program for International Student Assessment (PISA) [15, p. 46], the relationship was substantiated in a more official way.

At about the time of publication of KTEM, the National Academies of Science was asked to review and summarize the research on mathematics education, and to make recommendations for improving it. The report resulting from the study was Adding It Up, published in 2001 [13]. Two (of the five) recommendations in the report recognized the need for systematic, long-term effort to become a proficient mathematics teacher, and called for structures to address this need:

- Teachers' professional development should be high quality, sustained, and systematically designed to help all students develop mathematical proficiency. Schools should support, as a central part of teachers' work, engagement in sustained efforts to improve their mathematics instruction. This support requires the provision of time and resources.

- The coordination of curriculum, instructional materials, assessment, instruction, professional development, and school organization around the development of mathematical proficiency should drive school improvement efforts.

Somewhat later, NRC work also showed that there are even more systematic structures in place in the Chinese school system to support teacher learning. In 2009, ten years after publication of KTEM, the US National Commission for Mathematics Instruction (USNCMI) held a joint US-China workshop exploring the career structure of mathematics teachers in the two countries [14]. This workshop revealed a substantial infrastructure supporting teacher learning in China. In general, a Chinese teacher's career is more structured, and offers more opportunities for advancement, than is the case in the US. A standard teaching career moves through three ranks: second rank teacher, first rank teacher, and senior or master teacher. The movement from one rank to the next involves various formal requirements, including a substantial amount of continuing education, and for the master rank, publication of research, often on effective methods for teaching specific topics. Novice teachers are assigned senior mentors, who give advice on lesson plans and attend and give feedback on lessons taught by the novice teachers, who in turn will visit the classroom of their mentor teacher to observe and absorb effective teaching moves.

Further, beyond the normal three ranks, there are opportunities to become a "super-rank" teacher. The rules governing these higher ranks are not uniform across China but in a city like Shanghai (which has a population larger than New York State), the super-rank structure is quite systematic, and super-rank teachers form a specified (rather small, under $1 \%$ ) portion of all teachers. To become a super-rank teacher, one must publish on good teaching techniques for selected topics, and also compete in teaching contests. Besides teaching students, the job of superrank teachers involves running professional development for their normal rank colleagues. In this way, knowledge of effective teaching techniques and responsibility for propagating them is embodied in the teaching corps itself.

Consistent with the existence of the master and super ranks for teachers, with responsibility for professional development, there is a substantial system of continual professional development in place. Teachers participate in research groups in their schools or districts, and many research groups work on new teacher induction, preparing for rising to master teacher level, and discussion of effective teaching of various specific topics. The strong support for helping teachers improve highlighted in the 2009 
USNCMI workshop is also documented in a World Bank report [21].

The US has nothing comparable to this level of support for continued learning. Teachers who are determined to make the effort to improve are mainly left to their own devices. Moreover, there are few mechanisms for sharing anything that is learned.

One might have hoped that these structural deficits in the organization of US mathematics education, pointed to so clearly by Liping Ma and further reinforced by Adding It Up and then again by USNCMI, would have gotten the attention of US educational policymakers, and resulted in widespread reforms. Unfortunately for our teachers and their students, this has not happened. For example, when the Common Core State Standards for Mathematics (CCSSM) was rolled out around 2010, it was formally adopted by most states, but little to nothing was done to enable teachers to teach in the ways advocated by the CCSSM. New York did commission a project to create a text consistent with CCSSM, which resulted in Eureka Math (aka Engage New York) [8]. This has a lot of good points, including teacher editions with extensive discussions of the relevant mathematical ideas; but these teacher editions mostly run between 1,000 and 2,000 pages per grade. They clearly require intensive study, but arrangements to promote that study are mostly lacking.

The lack of support for teacher improvement in US education is more or less unchanged in the two decades since Liping Ma showed us the dramatic deficits of teacher mathematics expertise that results from it, and international examinations such as TIMSS and PISA have shown us that this translates into deficits in student learning. US education policymakers have not learned from this crosscultural research; they have preferred a top-down scheme of standardized tests, with punishments for submandated performance. So it should come as no surprise that, as recorded in the latest PISA (2018) results [18], our children continue not to learn mathematics very well.

Some might argue that these kinds of deficits are culturally determined, so that there is no possibility of matching Chinese levels of performance. However, there are examples closer to home of school systems that achieve better results in mathematics. In particular, Canada has consistently done better in international comparisons than the US [17]. Even more relevant for us is the experience of Massachusetts, which in the early 1990s had mathematics achievement that was fairly typical of the US, but which decided that that was not good enough, and embarked on a long-term effort to improve. The Massachusetts Education Reform Act of 1993 provided for increased funding to make opportunities to learn more equitable, substantial professional development, and higher mathematics requirements for teacher certification (thus impacting teacher preparation programs) [6]. It worked. Massachusetts now, considered as a separate country, has test scores significantly above the US average [20], [16], [11], [7]. Massachusetts also comes out at the top in the National Assessment of Educational Progress (NAEP), the US's own instrument for assessing student achievement. For example, in the 2019 edition of NAEP, Massachusetts eighth-graders had the highest overall average of any state, and perhaps more significantly, $48 \%$ of them scored at the proficient or advanced level [12]. Only two other states had over $40 \%$ at these levels. The rest of the country should take some lessons.

ACKNOWLEDGMENTS. The author is grateful to the referee for a careful reading and many helpful suggestions, which substantially improved the paper. Thanks also to Richard Bisk, Albert Cuoco, and Thomas Fortmann for information about Massachusetts.

\section{References}

[1] D. Ball, The Subject Matter Preparation of Prospective Teachers: Challenging the Myths, National Center for Research in Teacher Education, East Lansing, MI, 1988.

[2] D. Ball, Teaching Mathematics for Understanding: What Do Teachers Need to Know about the Subject Matter?, National Center for Research in Teacher Education, East Lansing, MI, 1989.

[3] D. Ball, Prospective elementary and secondary teachers' understanding of division, J. Res. Math. Ed. 21 (1990), 132144.

[4] D. L. Ball, S. T. Lubienski, and D. S. Mewborn, Research on teaching mathematics: the unsolved problem of teachers' mathematical knowledge. In V. Richardson (ed.), Handbook of research on teaching (4th ed), Macmillan, New York, 2001, pp. 433-456.

[5] Critical variables in mathematics education: Findings from a survey of empirical literature, MAA and NCTM, Washington, DC, 1979.

[6] M. Chester, Building on 20 Years of Massachusetts Education Reform, Massachusetts Board of Education, Boston, MA, 2014.

[7] Bringing it back home (Briefing paper \#410). https:// www.epi.org/publication/bringing-it-back -home-why-state-comparisons-are-more -useful-than-international-comparisons-for -improving-u-s-education-policy/

[8] Eureka Math.https://greatminds.org/math

[9] A Study Package for Examining and Tracking Changes In Teachers' Knowledge. Available at https://eric.ed .gov/?id=ED359170

[10] Liping Ma, Knowing and Teaching Elementary Mathematics, Lawrence Erlbaum Assoc. Inc., Mahwah, New Jersey; London, 1999. 
[11] Massachusetts students score among world leaders on PISA reading, science and math tests [Press release]. Www. doe . mass . edu/news/news . aspx?id=24050

[12] https://www. nationsreportcard.gov/ndecore /xp1ore/NDE

[13] J. Kilpatrick, J. Swafford, and B. Findell (eds.), Adding It Up: Helping Children Learn Mathematics, Mathematics Learning Study Committee, Center for Education, Division of Behavioral Sciences and Education, National Academies Press, Washington, DC, 2001.

[14] A. Ferreras and S. Olson, rapporteurs, A. E. Stein, ed., The Teacher Development Continuum in the United States and China, Summary of a Workshop, National Academies Press, Washington, DC, 2010.

[15] PISA 2012 Results: What Students Know and Can Do: Student Performance in Mathematics, Reading and Science (Volume I, Revised edition, February 2014), PISA, OECD Publishing. dx. doi .orq/10.1787/9789264208780-en

[16] https://www.oecd.org/pisa/PISA-2015 -United-States-MA.pdf

[17] https://www.oecd.org/pisa/publications /PISA2018_CN_CAN.pdf

[18] https://www.oecd.org/pisa/publications /PISA2018_CN_USA.pdf

[19] L. Shulman, Those who understand: Knowledge growth in teaching, Educational Researcher 15 (1986), 4-14.

[20] https://nces.ed.gov/timss/pdf/results11 _Massachusetts_Math.pdf

[21] World Bank study shows Shanghai's \#1 global ranking in reading, math, \& science rests on strone education system with great teachers [Press release]. https://www. wor 1dbank . orq/en/news/press-release/2016/05/16/world -bank-study-shows-shanghais-1-global-ranking -in-reading-math-science-rests-on-strong -education-system-with-great-teachers

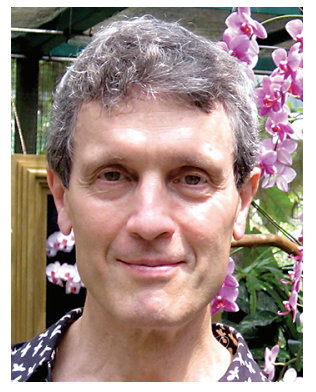

Roger Howe

\section{Credits}

Photo of Roger Howe is courtesy of Lyn Howe.

AMS AUTHOR RESOURCE CENTER

The Author Resource Center is a collection of information and tools available to assist you to successfully write, edit, illustrate, and publish your mathematical works.

\section{To begin utilizing these important resources, visit:}

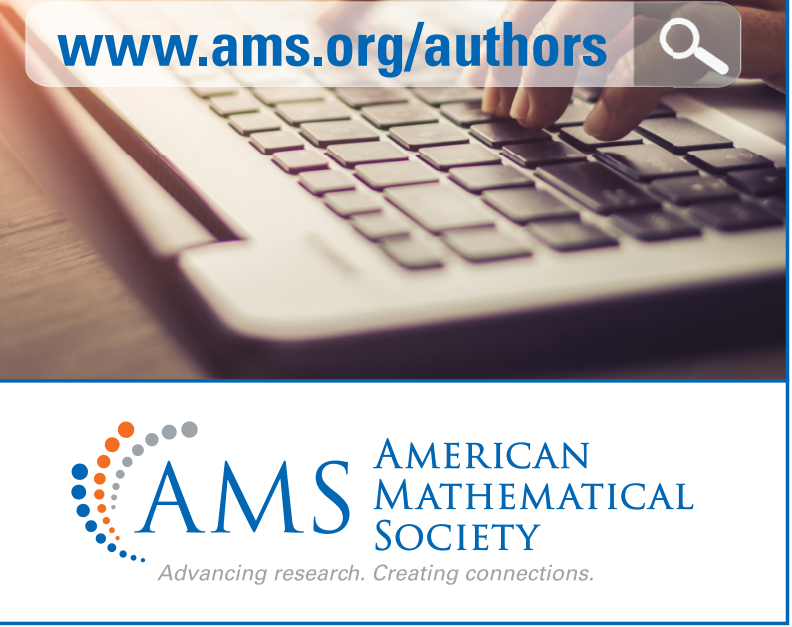

